\title{
Influence of Enterprise Culture Construction on Technological Innovation Ability Based on Deep Learning
}

\author{
Heng Yang ${ }^{1}$ and Luqi Wang $\mathbb{D}^{2}$ \\ ${ }^{1}$ Guangzhou Vocational College of Technology and Business, Guangzhou 511442, China \\ ${ }^{2}$ University of Melbournet, Grattan Street, Parkville, Victoria 3010, Australia \\ Correspondence should be addressed to Luqi Wang; luqiw@student.unimelb.edu.au
}

Received 25 November 2021; Revised 17 December 2021; Accepted 23 December 2021; Published 19 January 2022

Academic Editor: Hasan Ali Khattak

Copyright $\odot 2022$ Heng Yang and Luqi Wang. This is an open access article distributed under the Creative Commons Attribution License, which permits unrestricted use, distribution, and reproduction in any medium, provided the original work is properly cited.

\begin{abstract}
To better conform to the development trend of economic globalization, modern enterprises need to continuously innovate in technology, so as to provide enterprises with better products. The technological innovation level of economic innovation subjects is rising day by day, and the technological innovation level of enterprises has become more and more prominent. An excellent corporate culture will help technological innovation. The company uses corporate culture to shape its corporate image and spirit, thereby creating an atmosphere for technological innovation and bringing success to technological innovation. Corporate culture and technological innovation are two important elements to strengthen the company's core competitiveness, which directly affect the company's sustainable development level. Based on the previous analysis, we constructed an integrated model of corporate culture and technological innovation based on deep learning methods, analyzed the effect of corporate culture construction on corporate technological innovation capabilities, and sought measures to establish corporate culture.
\end{abstract}

\section{Introduction}

The strength of enterprise competitiveness is an important factor affecting international competitiveness. Great changes have taken place in the development environment of enterprises in the new era, and the competition is becoming more and fiercer, which makes the situation faced by enterprises more urgent. At this critical moment, enterprises urgently need reforms to obtain new development momentum and continuously improve their innovation. Creativity is, thus, invincible in market competition [1]. The spirit of innovation permeates all production and management activities of enterprises, affecting and restricting the survival, competition, and development of enterprises [2]. The unique ability which is not easy to be imitated by competitors and can bring excess profits is called core competitiveness [3]. The strength of core competitiveness determines the status and destiny of an enterprise in market competition. Corporate culture is the mission shouldered by all members of the company and the hardworking vision. It is a kind of value, which is gradually formed in the production practice of the enterprise, which is embodied in the production and operation of each link, integrated into the various management systems of the enterprise, not only internalized in each member, but also reflected in the external image of the enterprise in Ref. [4]. A good corporate culture often consciously guides employees to identify with the values of the company in practice, and gradually amend and consolidate them, eventually forming "invisible rules" that exist in the awareness of employees [5].

The key way out for enterprises is technological innovation, which has far-reaching effects on the development of enterprises [6]. Enterprise culture and technological innovation can be regarded as two important conditions to improve the core competitiveness of enterprises, which directly affect the sustainable development level of enterprises. At present, China's technological innovation ability is still weak, and it lacks high-end talents. Compared with the international average level, the conversion rate of scientific research achievements is low, and the scientific research 
funds are low [7]. To effectively carry out technological innovation, enterprises need entrepreneurial innovation and entrepreneurship, systematic and thorough strategic planning, and orderly organization and coordination to organize various functional areas and links into a whole [8].

The ability of an enterprise to continuously provide excellent products is inseparable from the results of scientific and technological innovation. An excellent corporate culture will help the company's technological innovation. Corporate culture promotes the success of technological innovation by shaping the corporate image and spirit of the enterprise and fostering an atmosphere of technological innovation [9]. The construction and optimization of socialist market economic system is based on the development of modern science and technology and modern market economy. How to survive and develop in the fierce competitive environment is an urgent problem faced by all enterprises [10]. Due to the special needs of knowledge and relearning, the practice of enterprise technological innovation in the construction of learning enterprise culture cannot be ignored [11]. Based on this, based on the deep learning method, it studies the impact of corporate cultural innovation on the company's technological innovation ability and understands how corporate cultural innovation can enhance the company's technological innovation ability.

The rest of the paper is arranged as Section 2 contains composition of technological innovation ability of enterprises, Section 3 focuses on the integration model of enterprise culture and technological innovation, Section 4 throws light on the construction of enterprise culture and the double wheel drive of enterprise science and technology innovation, and the final section is the concluding section.

\section{Composition of Technological Innovation Ability of Enterprises}

2.1. The Concept of Enterprise Technological Innovation Capability. Technological innovation ability is the comprehensive ability of enterprises to effectively utilize all kinds of resources for technological innovation under certain economic and technological conditions, aiming at enhancing their competitiveness and improving their quality of enterprise. Technology and knowledge are closely linked. The essence of enterprise's technological capability is knowledge. Advanced knowledge is needed as the basis in the stage of enterprise's technological innovation. The choice of the company's technological innovation strategy is closely related to its innovation ability [12]. On the one hand, the choice of innovation strategy should be based on the company's technological innovation resources and technological innovation ability. On the other hand, the correct choice of enterprise innovation strategy directly affects the progress of enterprise's technological innovation ability. Through the construction of corporate culture, the best human resource allocation is realized and the team consciousness is improved. Statistics show that $80 \%$ of innovators who produce technological innovation only account for $20 \%$ of the company's employees, and come from all departments of the company [13]. The technological innovation ability of a company corresponds to a specific company size. Large enterprises are better at technological innovation. If the company wants to make a breakthrough in reform and development, it must first give up the thinking mode formed under the situation of planned economy and then realize the innovation of management concept adapting to the production of market economy.

\subsection{The Constitution of Technological Innovation Ability of} Scientific and Technological Enterprises. The technological innovation level of enterprises is generally influenced by R\&D level, manufacturing level, marketing level, and innovation management level. The composition of technological innovation capability is obtained from the composition conditions of technological innovation capability of science and technology enterprises, as shown in Figure 1.

2.2.1. R\&D Capability. Research and development (R\&D) capability is the comprehensive capability of modern companies in science and technology research, technology development, and application [14]. R\&D capability is different from the resource input capability of enterprises, and it pays more attention to the achievements of technological innovation. To make the enterprise survive and develop is the main goal of the enterprise managers. Therefore, the enterprise must reserve the innovation potential and seize the opportunity to carry out innovation. In the formation stage of corporate culture, the company will deepen internal communication and learning through training and education. In this way, you can not only improve the professional skills of employees but also improve the professional skills of employees and effectively realize the whole R\&D plan of the company. Assimilation, absorption, and reinnovation activities are classified as R\&D activities of imported technologies. Therefore, as one of the indexes of $\mathrm{R} \& \mathrm{D}$ function, the innovative function after digestion and absorption can be used. R\&D skills are the foundation of technological innovation ability of technology companies. This is because the basic research, applied research, and development research of R\&D capability are the basic sources of technological innovation capability. Every enterprise has its own ideas, and entrepreneurs are working hard for this idea. Entrepreneurial spirit guides the company's development direction from a strategic and macro perspective. It directly affects the development and management of scientific research.

2.2.2. Manufacturing Capability. The manufacturing capability of the company covers the overall production level of the company, the advanced level of equipment, the level of equipment and information organization, the level of testing and standardization, and the proportion of senior technicians. The manufacturing capacity required by technological innovation of science and technology enterprises is different from the existing manufacturing capacity. The 


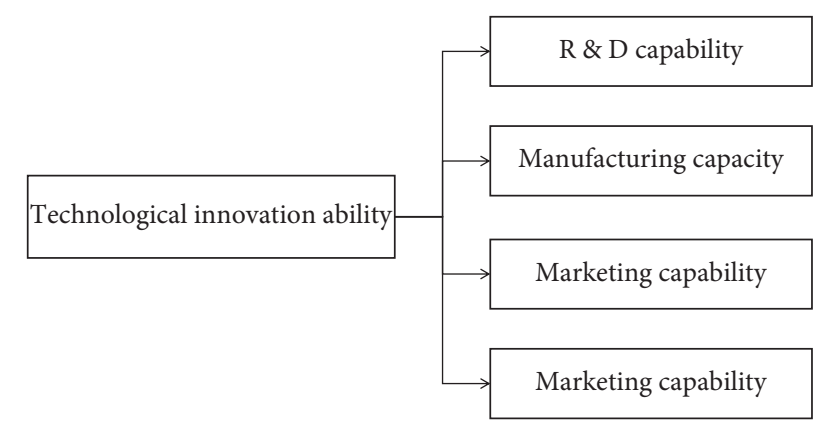

FIGURE 1: Composition of technological innovation capability level of enterprises.

manufacturing capability required by technological innovation refers to the manufacturing capability that can realize technological innovation [15]. If we want to improve the technological innovation ability of enterprises, it is necessary to improve the manufacturing level of enterprises, so as to ensure the advancement of enterprise facilities, the adaptability of employees' technological level and technological innovation, the technological research and development level of enterprises, and the corresponding management ability. Only by combining with the personnel who meet the manufacturing requirements, we can give full play to the advanced nature of the equipment. From easy to difficult, enterprises can start with product design and appearance packaging, even if it is novel, it can bring different consumption experiences to consumers and bring unexpected benefits to enterprises. Enterprises can make use of continuous scientific and technological innovation to innovate the original production technology, so as to control costs, ensure product quality, and let consumers get a good shopping experience. In this way, the brand and products of the enterprise can be truly played out and gain a larger market share.

2.2.3. Marketing Capability. Technological innovation is to create greater profits, and the level of marketing realization directly determines whether new products or services can be finally transformed into profit results. Therefore, the level of marketing realization is a very important link, which can reflect whether consumers accept this new product or service. Marketing ability includes two aspects: market research ability and sales ability. Technological innovation needs market research ability first, which cannot be replaced by the experience of sales staff. In the research process of a mature enterprise, it is found that the common factor for these enterprises to maintain lasting technological innovation vitality is to have a corporate culture suitable for their own development, which is the guarantee of research and marketing, and is more important than $\mathrm{R} \& \mathrm{D}$ or marketing. Marketing ability is to promote products or services through various publicity, such as advertising media, product experience, etc., so that consumers can know and recognize new products, and feedback their feelings and suggestions to enterprises, so as to realize the transformation of innovative achievements [16].
2.2.4. Innovation Management Ability. Innovation management level is the comprehensive ability of a company to find innovation opportunities, and help and manage technological innovation. Management innovation ability is the ability of a company to find and evaluate technological innovation opportunities and organize and manage innovation activities. It is of great significance in the process of constructing and implementing the function of technological innovation. Management should proceed from the overall situation and give attention to details, so as to ensure the realization of technological innovation decision. An effective innovation mechanism can make innovators make the best use of their talents, communicate smoothly, and cooperate effectively. Accelerating innovation is a historical trend. The time from invention to application of science and technology is getting shorter and shorter, and the distance between basic research and commercial application is getting closer and closer. This is a common phenomenon in the field of modern high technology. In order to improve the innovation mechanism, the leadership of the company must establish an innovation incentive mechanism, encourage employees to put forward new ideas and ideas, and tolerate errors and defects in the innovation process to enhance the company's technological innovation ability. As shown in the table, the time and income of the results enter the market.

\section{Integration Model of Enterprise Culture and Technological Innovation}

Enterprises registered in China, except Hong Kong, Macao, and Taiwan, have independent intellectual property rights over important technologies of their products or services in the last three years by means of transferee, independent research and development, etc. The number of employees with college degree or above in technical positions of enterprises should reach more than $26 \%$ of all employees, and the employees engaged in R\&D positions should reach more than $7 \%$ of all employees. For example, Table 1 is the ratio of R\&D investment to total sales of enterprises.

Fund management is the top priority of financial management, but a considerable number of group enterprises have loose fund management due to the limitation of management mode and means. The operating performance of a company from 2011 to 2020 is shown in Figure 2.

For enterprises, a recognized source of price advantage is enterprise scale. When there are significant economies of scale, the relationship between enterprise scale and cost is shown in Figure 3.

Deep learning refers to a continuous learning process in which critical thinking is carried out on the basis of understanding knowledge and mastering its structure and essence, and knowledge is further processed, applied, and created. Enterprise values are gradually formed in the long practice, which is the core part of enterprise culture. It integrates the value orientation of all employees in the enterprise, is the code of conduct they abide by in their daily actions, and provides internal motivation for the survival and development of the enterprise. Deep learning is not simply to acquire knowledge and broaden horizons but to 
TABLE 1: Ratio requirements of R\&D investment to total sales.

\begin{tabular}{lc}
\hline $\begin{array}{l}\text { Sales volume in the latest year } \\
(10000 \text { yuan })\end{array}$ & $\begin{array}{c}\text { Total R\&D investment/sales } \\
\text { revenue (\%) }\end{array}$ \\
\hline Less than 7000 & 9 \\
$7000-23000$ & 9 \\
Over 23000 & 3
\end{tabular}

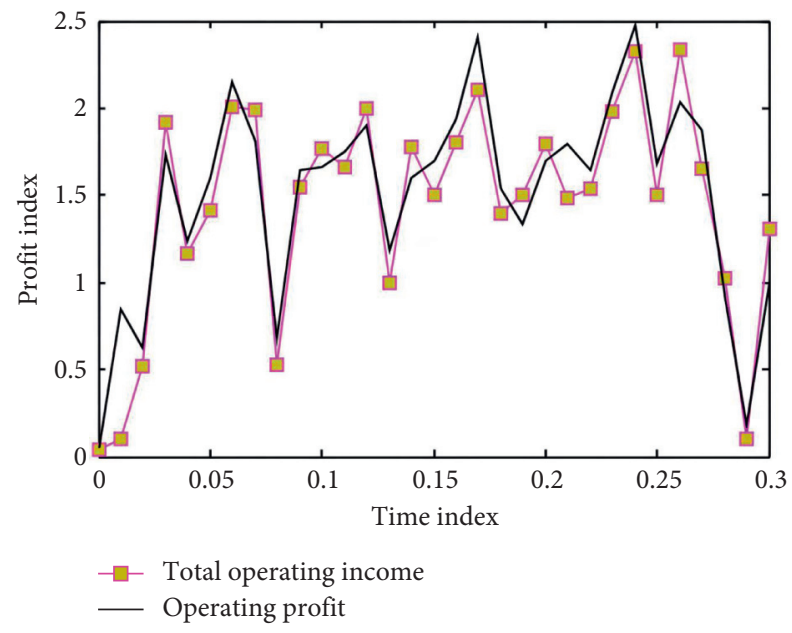

Figure 2: Operating performance.

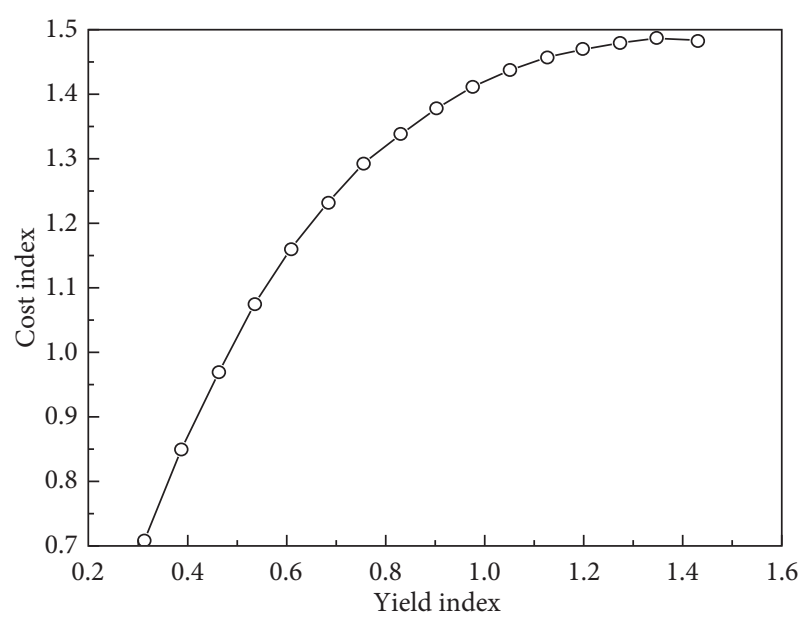

FIGURE 3: The relationship between enterprise scale and cost.

improve students' ability to use knowledge to discover, analyze, and solve problems on the basis of understanding knowledge. Deep learning needs to be digested and absorbed in acquiring knowledge and is good at transferring knowledge to a new situation and applying it on the basis of understanding its profound connotation. The absorption and introduction of innovative talents will inevitably greatly promote the development and progress of enterprises, inject new vitality into enterprises, and provide important conditions for the development of technological innovation activities of enterprises. The scale, level, emphasis, and mode of technological innovation of enterprises are often guided by their values. Enterprise values are a link, which can condense the spiritual level of employees through invisible power. It can promote the development of enterprise technology innovation capacity and serve as a guide direction. The structure of the deep learning neural network model in this article is shown in Figure 4.

Suppose $\psi(x) \in L^{2}(R), L^{2}(R)$ is the square integrable function space, and the Fourier $\psi(\omega)$ transform satisfies the condition:

$$
\int_{R}\left(\frac{|\psi(\omega)|^{2}}{\omega} d \omega<\infty\right) .
$$

The corresponding equivalent conditions are as follows:

$$
\int_{-\infty}^{+\infty} \psi(x) d x=0
$$

Call $\psi(x)$ a basic wavelet or a wavelet mother function and call the above formula the admissible condition of the wavelet function.

At the stage of establishing the structure of enterprise financial early warning control, the procedure, method, and index system of the system need to be scientific and reasonable. As shown in Figure 5, we can see the deep learning structure of enterprise risk early warning.

The neural network structure discussed contains two hidden layers, and the number of hidden layers is determined by the following methods:

$$
\begin{aligned}
& M=\sqrt{s+t}+\alpha, \\
& M=\log _{2} s, \\
& M=\sqrt{s \cdot t},
\end{aligned}
$$

$S$ and $t$ represent nodes in the output layer and the input layer, respectively, and $\alpha$ can be a value between 1 and 10 . The experimental results are shown in Table 2.

Empirical analysis shows that the financial risk early warning model based on deep learning can keep the accuracy of predicting whether an enterprise will fall into financial crisis above $73 \%$, and the greater the data usage, the higher the prediction accuracy.

The later the innovation results enter the market, the more the potential total revenue decreases. Entering the market earlier, the income increases significantly. It is precisely because of the existence of interest relationship that the speed of innovation is highly valued by western business circles as shown in Table 3.

It can be seen from Table 4 that the index value of each variable of technological innovation capability of China's science and technology enterprises is relatively high. However, there is a problem that the innovation input capacity is the strongest, while the innovation output capacity is weak, so we should pay attention to this situation that the input and output are not directly proportional.

The results of descriptive statistics of enterprise culture show that the innovation incentive system of science and technology enterprises needs to be strengthened.

It can be seen from Table 5 that the scores of innovation values of science and technology enterprises are the highest, reaching 3.8321, the scores of innovation atmosphere are 3.4738 , and the survey scores of innovation 


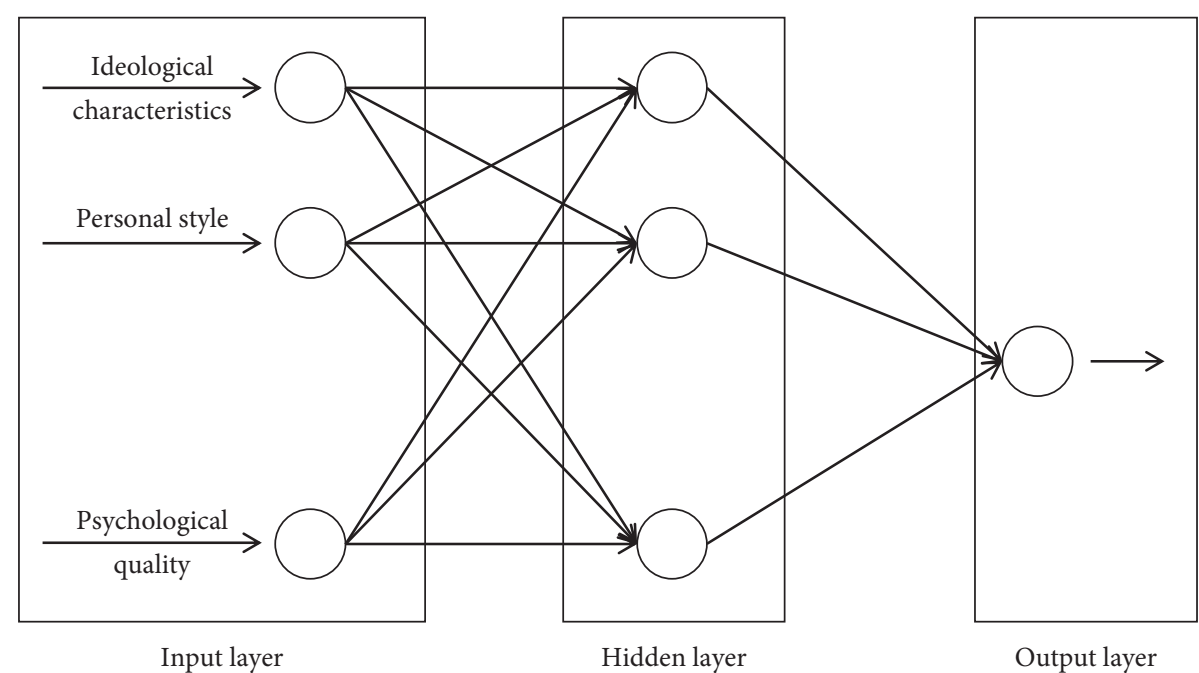

Figure 4: Neural network model.

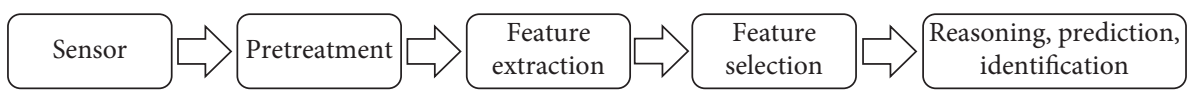

FIGURE 5: Deep learning hierarchy.

TABLE 2: Empirical results.

Demonstration group

Correct rate $(\%)$

1 years

TABLE 3: Time and benefits of the results entering the market.

Backward entry into the market

\begin{tabular}{cccccc}
6 months & 5 months & 4 months & 3 months & 2 months & 1 month \\
\hline-34 & -26 & -19 & -13 & -8 & -4 \\
12.1 & 9.4 & 7.5 & 5.8 & 4.5 & 3.2
\end{tabular}

Potential total revenue decreases during the product life cy
Entering the market and increasing income in advance (\%)

TABLE 4: Descriptive statistics of each variable of technological innovation capability.

\begin{tabular}{lcccc}
\hline & Minimum value & Maximum value & Mean value & Standard deviation \\
\hline R\&D ability & 1.01 & 5.00 & 3.5738 & 0.9538 \\
Manufacturing ability & 1.14 & 4.30 & 2.7325 & 0.6329 \\
Innovation input ability & 1.35 & 4.85 & 3.6882 & 1.2403 \\
Marketing ability & 1.13 & 5.00 & 3.6103 & 0.7459 \\
Innovative management ability & 1.82 & 4.59 & 3.5952 & 0.7836 \\
Innovation output ability & 1.32 & 4.69 & 2.6173 & 1.1102 \\
\hline
\end{tabular}

TABle 5: Descriptive statistics of various variables of corporate culture.

\begin{tabular}{lcccc}
\hline & Minimum value & Maximum value & Mean value & Standard deviation \\
\hline Enterprise innovation values & 2.11 & 5.00 & 3.8321 & 0.8854 \\
Enterprise innovation incentive system & 1.23 & 4.46 & 2.5959 & 0.7859 \\
Enterprise innovation atmosphere & 1.95 & 4.89 & 3.4738 & 0.6686 \\
\hline
\end{tabular}

incentive system are low, only 2.5959. This shows that the innovation values and atmosphere of science and technology enterprises are strong, but the incentive of enterprise culture construction is not enough, which needs to be further strengthened.
After establishing the target industry's risk investment index system, the analytic hierarchy process can be used to comprehensively evaluate the project risk. According to the sample data, the results of the weight value and evaluation value data are sorted out as shown in Figure 6. 


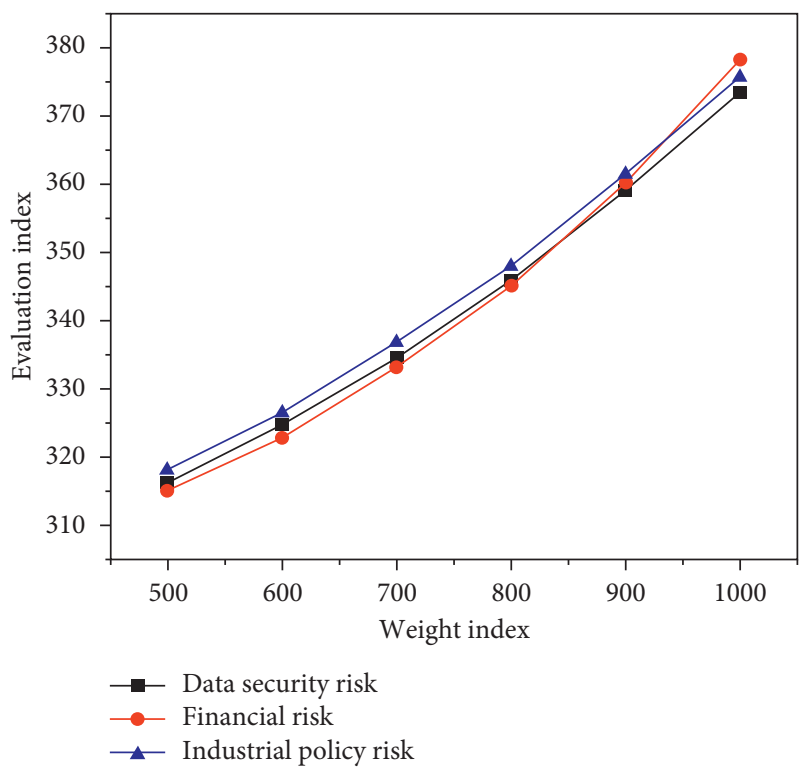

FIGURE 6: Data relationship between the weight value and the evaluation value.

Deep learning can deeply understand the core content of knowledge, transfer it to new tasks and situations, and apply theories, principles, and methods to the real world. This will help students understand the interaction between explicit knowledge and tacit knowledge, promote students' flexible transformation between explicit knowledge and tacit knowledge, and improve students' knowledge transformation ability. The stock market has an effect on stock quality through stock price. As a commodity in market economy, its price is also affected by the relationship between supply and demand of commodities. Manufacturing level is an important index of technical innovation capacity, and it is the ability of enterprises to transform research and development achievements into products in a certain period of time. The ideas and technologies generated in the R\&D stage must be put into practice, which must be realized by the manufacturing level of the enterprise. The key factor of unsuccessful network training is the unreasonable setting of initial connection weights, which makes the minimum value of model training deviate greatly from the initial state, or it may be that too many extreme values in the model lead to too long training time. The importance attached by enterprises to innovative talents is the embodiment of enterprise values, which have a direct impact on technological innovation output ability, technological innovation input ability, and technological innovation management ability. Therefore, the development degree of enterprise human resources has a direct impact on enterprise technological innovation activities. The data mining process in financial analysis generally consists of five main stages: determining financial analysis objects, data preparation, data mining, result analysis, and knowledge assimilation, as shown in Figure 7.

Let the expected output be $z_{k}^{\prime}$ and define the global error between the expected and actual output as L:

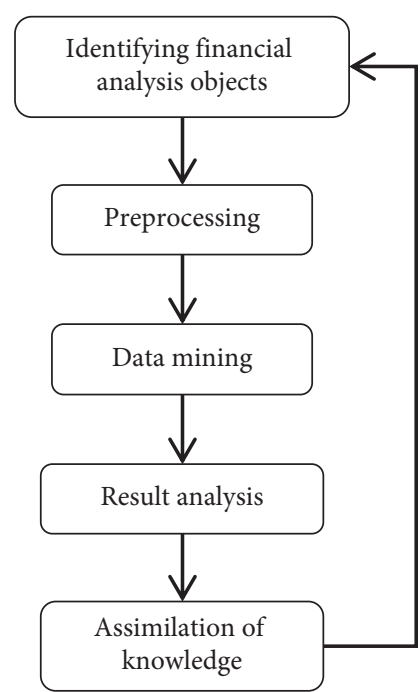

FIgURE 7: Data mining process in financial analysis and management.

$$
L=\frac{1}{2} \sum_{k=1}^{m}\left(z_{k}-z_{k}^{\prime}\right)^{2}
$$

Through the process of back propagation, the error expands to the hidden layer as follows:

$$
\begin{aligned}
L & =\frac{1}{2} \sum_{k=1}^{m}\left[f\left(\lambda_{k}\right)-z_{k}^{\prime}\right]^{2} \\
& =\frac{1}{2} \sum_{k=1}^{m}\left[f\left(\sum_{k=1}^{t} w_{j k} y_{j}+b_{k}\right)-z_{k}^{\prime}\right]^{2} .
\end{aligned}
$$
follows:

The final backward transmission to the input layer is as

$$
\begin{aligned}
L & =\frac{1}{2} \sum_{k=1}^{m}\left[f\left(\sum_{k=1}^{t} w_{j k} y_{j}+b_{k}\right)-z_{k}^{\prime}\right]^{2} \\
& =\frac{1}{2} \sum_{k=1}^{m}\left[f\left(\sum_{k=1}^{t} w_{j k}\left(\sum_{j=1}^{n} w_{i j} a_{i}+b_{j}\right)+b_{k}\right)-z_{k}^{\prime}\right]^{2} .
\end{aligned}
$$

The network error is a function of the weights $w_{i j}$ and $w_{j k}$, so the error $\varepsilon$ can be changed by changing the neuron weight, which is as follows:

$$
\begin{aligned}
\Delta w_{i j} & =-\varepsilon \frac{\partial L}{\partial w_{i j}}(i=1 \ldots m, j=1 \ldots n), \\
\Delta w_{j k} & =-\varepsilon \frac{\partial L}{\partial w_{j k}}(j=1 \ldots n, k=1 \ldots t),
\end{aligned}
$$

where $\varepsilon$ is the rate and $\varepsilon \in(0,1)$.

In order to strengthen the safety awareness, the management experience of safety technology of each mine should be regularly exchanged and summarized, and the experience of safety technology culture should be actively applied to practice. Strengthen the education of safety culture for 
employees to make them realize the importance of safety culture and cultivate their safe working habits. Under the new normal of China's economy, the national economy is gradually transforming, and the mode of economic growth is gradually changing from resource consumption to innovation driven. Corporate culture reflects the values, common consciousness, professional ethics, and code of conduct and standards of an enterprise. The establishment of innovative values plays a very important role in the development direction of enterprise technological innovation. Enterprises should adhere to the concept of independent innovation and scientific development, actively support activities conducive to technological innovation, coordinate and cooperate with all departments, and create a policy environment conducive to technological innovation. In order to obtain huge profits, some investors may take some improper measures to manipulate the stock price, which may cause the stock price to fluctuate violently, which often appears in the real stock market. In the era of Internet economy, it is very convenient to acquire knowledge. Deep learning is to integrate, utilize, and create this massive and fragmented knowledge, so as to improve students' knowledge creation ability, and then improve their innovation and entrepreneurship ability. Only when the vast majority of employees of the enterprise integrate the values of technological innovation into the daily production and operation activities, can we form a common code of conduct and greatly promote the technological innovation activities of enterprises.

Suppose that it is necessary to judge which of the two candidate targets $i$ and $j$ is more in line with the requirements, and their characteristic representations are $n$-dimensional vectors $V_{i}$ and $V_{j}$, respectively. If linear regression is used to predict, the probability that $i$ is better than $j$ can be expressed as

$$
p(i>j)=g\left(W^{T} V_{i}-W^{T} V_{j}\right)
$$

where $W$ is an $n$-dimensional weight vector, and the $g(\cdot)$ nonlinear function is generally selected as the Sigmoid function:

$$
g(x)=\frac{1}{1+e^{-x}}
$$

Then the Bayesian personalized ranking needs to maximize the probability that $i$ is better than $J$, and the objective function is expressed as

$$
\begin{aligned}
\max _{x} J & =p(i>j) \\
& =g\left[W^{T}\left(V_{t}-V_{j}\right)\right] \\
& =\frac{1}{1+e^{-w^{T}\left(V_{i}-V_{j}\right)}} .
\end{aligned}
$$

Deep learning is a process of continuously optimizing learning strategies, which is a cyclic process from unbalanced learning to balanced learning. In the cyclic process, learners can always find the best learning state. The corporate culture atmosphere reflects the traditional habits and behavior mode of an enterprise. It is invisible, and every employee can feel the overall pursuit and spirit. It affects the daily management of enterprises, the value concept of employees, and the production and operation innovation of enterprises. Lead technological innovation with safety issues, respect the law of productivity development, turn the problems encountered in production safety into the motive force and goal of technological innovation, and apply the achievements of technological innovation to the actual production of enterprises. The enterprise culture with entrepreneurship as the core is the culture of pursuing innovation, development, change, and excellence, which determines the value orientation of enterprise technological innovation. The regional and industrial factors are considering the industry and region of the listed company. If the industry is in the rising period and has a good prospect, the stock price will rise, which may belong to the high-quality potential stocks. If the regional transportation is developed and the communication is convenient, the stock price will show an upward trend compared with the backward areas. To do a good job in training and education for enterprise employees can not only help employees to implement their own value but also can improve their knowledge and skills. The improvement of employees' comprehensive quality makes their potential to be tapped to a greater extent, stimulates innovative thinking, and has an important impact on the technological innovation activities of enterprises. College Students' innovation and entrepreneurship not only need risk-taking spirit and social responsibility but also need to have innovative consciousness and innovative ability.

According to the final error, it is transmitted back to the first hidden layer, and the connection weight of each neuron is adjusted layer by layer through the following formula. The error of the node at the same layer is calculated as $\delta_{k}$, and the adjustment formula is as follows:

$$
w_{j k}(1+t)=w_{j k}(t)+\varepsilon \delta_{k} o_{j} .
$$

Suppose that the input is $x_{h}$, the input of RNN should be an entire sequence $x=\left(x_{0}, x_{1} \ldots x_{h-1}, x_{h}, x_{h+1} \ldots x_{H}\right)$. Among them, $s_{t}$ represents the hidden state at time $t ; o_{t}$ represents the output at time $t ; u, w$, and $v$ represent weights, and the original data are abstracted and transferred to the network; $w$ has a memory function; and $v$ abstracts the features learned by the hidden layer output network after processing. Initialize each parameter and then move forward according to the following formula to make serialized predictions:

$$
\begin{aligned}
a_{1} & =u x_{1}+w s_{0}, s_{1} \\
& =f\left(a_{1}\right), o_{1} \\
& =g\left(v s_{1}\right), \\
& \ldots \\
a_{t} & =u x_{t}+w s_{t-1}, s_{t} \\
& =f\left(u x_{t}+w s_{t-1}\right), o_{t} \\
& =g\left(v s_{t}\right),
\end{aligned}
$$


where $f$ and $g$ are activation functions. The memory function of RNN is mainly reflected in the calculation of st. It summarizes the past input through $w$ and assists the next input.

The traditional organizational structure of the company has been unable to meet the needs of the development of the market economy. For the fierce competition and volatile market, enterprises need to actively innovate the organizational structure and effectively optimize the organizational structure, so as to provide a theoretical basis for the progress of enterprises. Comprehensive economic strength refers to all the economic strength, economic development potential, and economic status and influence of the region. The second principal component can be used to identify whether the city has a larger proportion of public facilities, infrastructure, and administrative investment, or whether the city has a higher income level, a consumption level, and a living standard. In the economic model, the linear regression curve is calculated according to the stepwise multiple linear regression equation, as shown in Figure 8.

The key to college students' innovation and entrepreneurship ability is to have knowledge creative ability. Knowledge creation can help students put forward new ideas, seize new market opportunities, use new methods to develop existing markets, and creatively solve many drawbacks such as resource shortage, experience shortage, and market disapproval of new ventures. Innovation values improve the technological innovation capacity by promoting the Group's R\&D capability, innovation input capability, innovation management capability, and innovation output capability. The development of an enterprise itself is an important influence on the stock quality. The organizational structure, staff composition, the rationality of the company's production and operation management, the innovation and competitiveness of products or services, the profitability, and the financial status are all manifestations of the enterprise's development status, which directly affect the stock price and stock quality.

For special problems, the original variable contains two contents. One part is a linear function of general factors that cannot be directly observed, and the other part is a special factor independent of general factors. It will stop when the maximum number of iterations is reached and the total length is equal to the number of analyzed functional requirements. The search result analysis is shown in Figure 9.

In-depth learning means that after students have defined their learning objectives, they can acquire the required knowledge in a targeted way. Deep learning will enable students to know what kind of knowledge they need, where they can search for the required knowledge, what value they will have in acquiring this knowledge, and what problems they can solve, which will avoid falling into massive knowledge and lose their direction and improve students' learning efficiency. At different stages, the competitiveness of industrial clusters and the specific performance of the competitiveness of industrial clusters at different stages are shown in Figure 10.

Making a set of scientific and reasonable income distribution policies is a must for every enterprise that wants to take the lead by relying on technological innovation in the

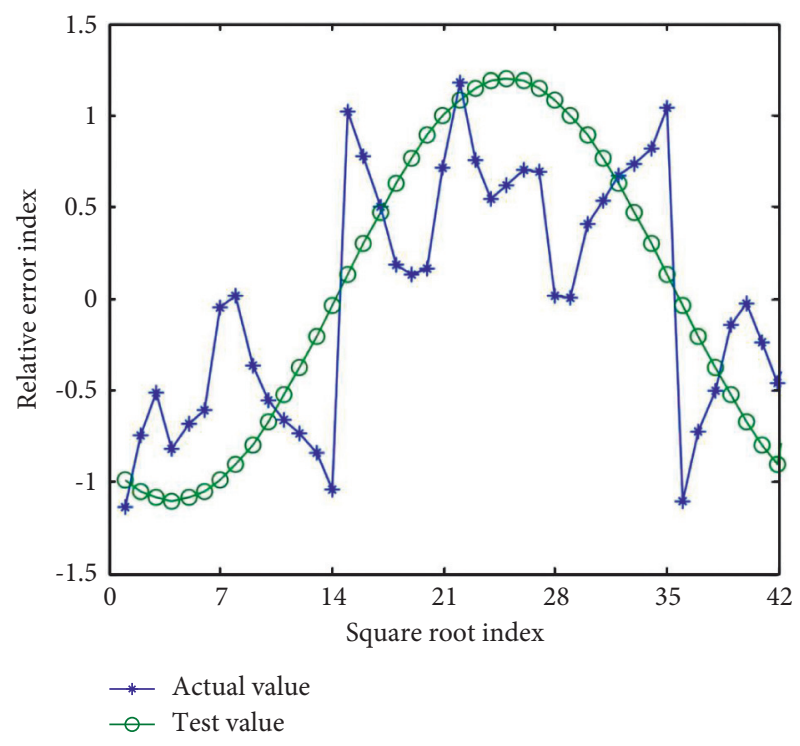

FIGURE 8: Relationship between the actual value and the calculated value of stepwise linear regression.

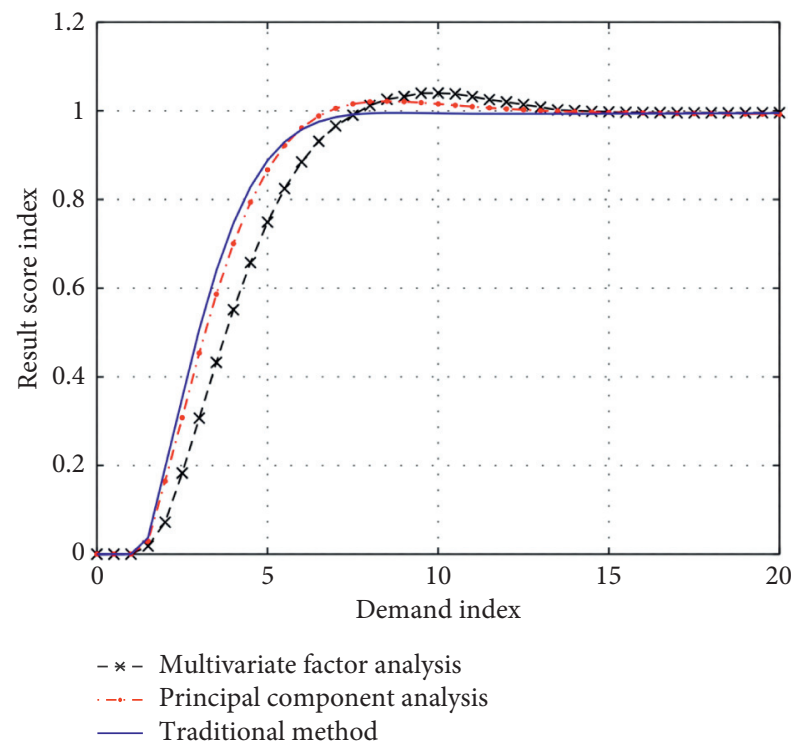

FIGURE 9: Score comparison of component retrieval results.

market. If an enterprise only has innovative values and innovative spirit, but lacks necessary institutional arrangements and implementation, then the innovation of an enterprise can only stay in concept. The key of deep learning is to learn knowledge critically and integrate it into the original knowledge structure, grasp the core of knowledge and transfer it to new situations. The speed of enterprise development and the level of management are largely determined by the quality of employees, and training plays a decisive role in improving the quality of employees. Only through training and education can employees master science and technology better, and employees apply their knowledge to the actual production and operation of coal mining enterprises, thus promoting the productivity of enterprises. 


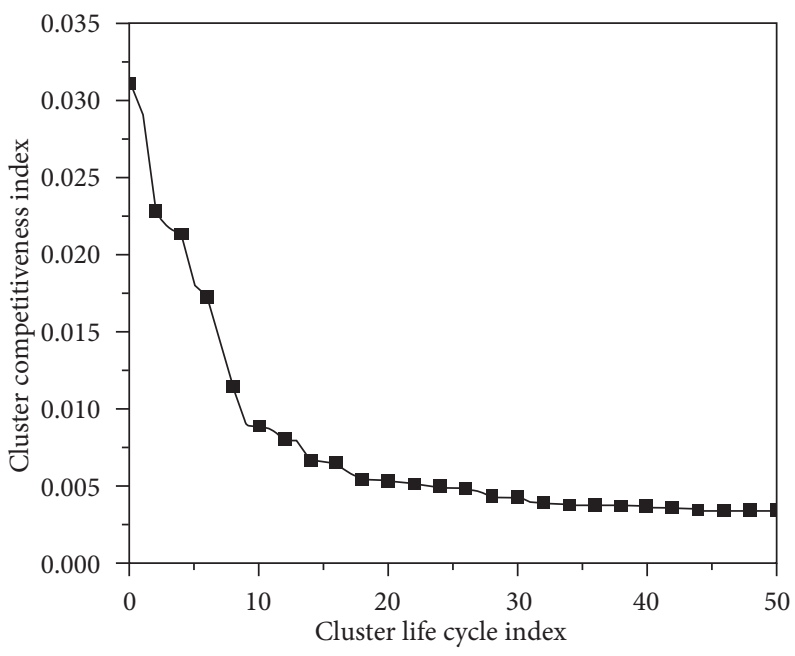

Figure 10: Trends of cluster competitiveness.

\section{The Construction of Enterprise Culture and the Double Wheel Drive of Enterprise Science and Technology Innovation}

Corporate culture is divided into three elements: corporate value, corporate culture, and corporate spirit. Technological innovation capabilities include R\&D level, manufacturing capability level, marketing level, and innovation management level. Based on the above analysis of the relationship between corporate culture and technological innovation capabilities, the relationship model between corporate culture and technological innovation capabilities as shown in Figure 11 is constructed.

4.1. The Foreshadowing Effect of Enterprise Culture on Scientific and Technological Innovation. People-oriented is the core idea of developing distinctive enterprise culture. The construction of enterprise culture can fully mobilize the enthusiasm and autonomy of enterprise personnel, provide a good atmosphere for employees to stimulate their own potential, and establish team consciousness. Technical innovation education is the training of employees who are determined to be entrepreneurs and those who are engaged in technical innovation in terms of technical innovation awareness, innovative methods and skills, innovative project evaluation, and market opportunities. Through education, they can enhance their ability and interest in participating in technical activities. Good corporate culture needs a good carrier of corporate practice, and those who try to create corporate culture through false forms often fail to achieve good results [17].

Taking the statistical results of technological innovation capability parameters as the research object, we deal with data clustering and information fusion. Table 6 shows the test results of the indicators.

After obtaining the result of data clustering, evaluate the result of clustering from the two parts of purity and entropy. The purity of each cluster is expressed as

$$
\text { purity }_{i}=\max \left(p_{i j}\right) .
$$

$p_{i j}$ refers to the probability that a member instance in cluster $i$ belongs to class $j, i, j=1,2, \ldots, 10, i \neq j$, and $p_{i j}=m_{i j} / m_{i}$, where $m_{i}$ is the number of all members in cluster $i, m_{i j}$ is the number of members in cluster $i$ belonging to $j$, and the purity of the entire cluster division is as follows:

$$
\text { purity }=\sum_{i=1}^{K} \frac{m_{i}}{m} \text { purity }_{i} \text {. }
$$

$k$ is the number of clusters, and $m$ is the number of members involved in the entire cluster member. The entropy of each cluster can be expressed as

$$
\text { entorpy }_{i}=-\sum_{j=1}^{L} p_{i j} \log _{2} p_{i j} \text {. }
$$

Here, $L$ is the number of classes, how many classes are in each cluster, and the entropy of the entire cluster is as follows:

$$
\text { entorpy }=\sum_{i=1}^{K} \frac{m_{i}}{m} \text { entropy }_{i} \text {. }
$$

The financial status risk comparison data are shown in Table 7. Figure 12 shows the relationship between the financial status risk weight value and the evaluation value data.

For employees who play a role in the technological innovation of the company, they can use the company culture to guide by values, ideals, and behaviors, so as to form a code of conduct and seek value according to the overall development of the company. A good corporate culture can provide powerful spiritual support for employees' scientific and technological innovation, thus making employees have positive subjective initiative in behavior. From the market practice, we can see that if a product can meet certain quality requirements, the success of competition usually depends on the cultural connotation of the 


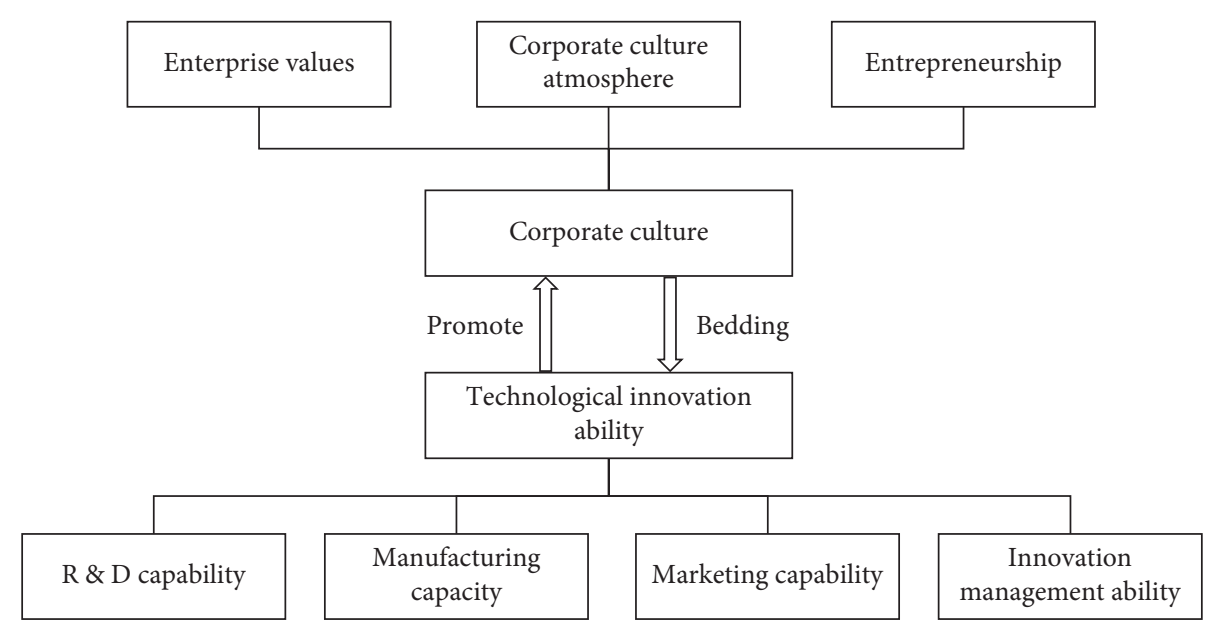

FIGURE 11: The relationship between corporate culture and corporate technological innovation capabilities.

TABLE 6: Evaluation test data.

\begin{tabular}{lcccccc}
\hline Stage & 1 & 2 & 3 & 4 & 5 & 6 \\
\hline Frequency & 78.41 & 75.89 & 70.30 & 83.25 & 78.90 & 69.71 \\
Accuracy & 81.57 & 88.78 & 87.64 & 87.26 & 86.37 & 89.25 \\
\hline
\end{tabular}

TABLE 7: Results of financial status risk comparison data.

\begin{tabular}{lcc}
\hline & Return on assets & Marginal cost rate \\
\hline Return on assets & 0.57 & 0.73 \\
Marginal cost rate & 0.46 & 0.62 \\
\hline
\end{tabular}

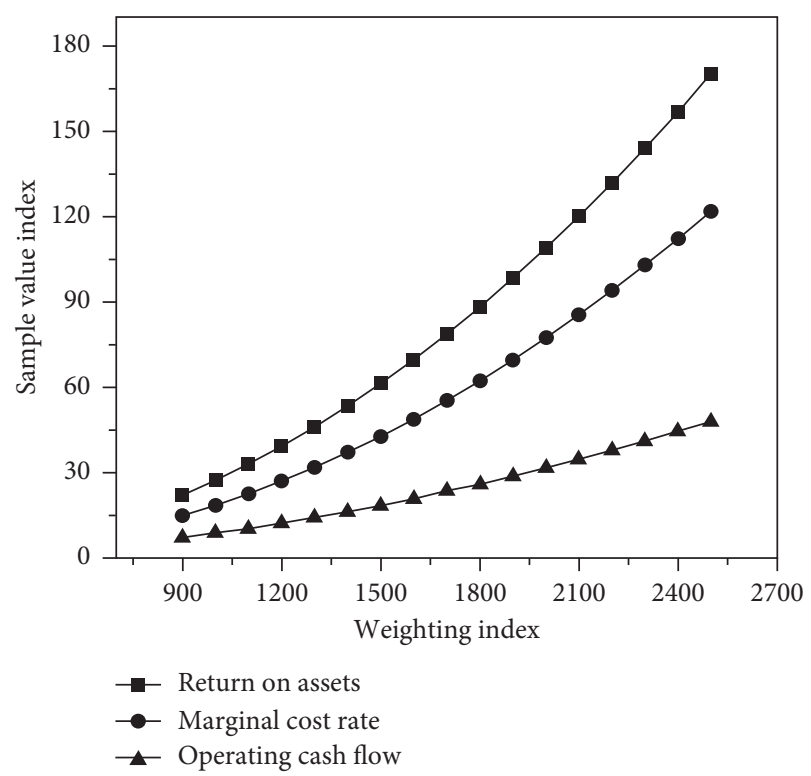

FIGURE 12: The relationship between the financial position risk weight value and the evaluation value data.

product. Therefore, technology companies need to build and rely on their own advanced corporate culture, so as to improve marketing skills and enhance technological innovation capabilities [18]. The technological innovation process of an enterprise is a process that needs strong support from the enterprise spirit, and it is also a process of training the enterprise spirit. If the enterprise culture can be peopleoriented, the enterprise can truly realize the value of talents for the development of the enterprise and can pave more powerful conditions for talents in continuous development and scientific and technological innovation.

\subsection{The Role of Science and Technology Innovation in Pro-} moting the Construction of Enterprise Culture. Technological innovation is the fundamental driving force to promote the progress of the whole society. Similarly, companies need to rely on technological innovation to achieve sustainable development and stabilize their position in the fierce competition. The lack of high-quality scientific and technical personnel and management personnel with innovative ability is the key factor that causes the weak technological innovation ability of the company. Therefore, cultivating and introducing innovative talents is the key to improve the technological innovation level of the company. To some extent, the users' demands faced by enterprises determine the goal of technological innovation. With the progress of enterprises, enterprises should make use of technological innovation to improve product quality and production efficiency and realize the commercialization of enterprises [19]. The risk index system of innovative hightech enterprises is established, and the risk is evaluated by AHP. The judgment matrix of weights is constructed. The data relationship between the weight value and the evaluation value is shown in Figure 13. Figure 14 shows the data relationship between the financial position risk weight value and the evaluation value.

Science and technology-based enterprises should emancipate their minds, and according to the actual results achieved by technological innovation and product development activities and the actual needs of meritorious personnel, they should be rewarded economically, so as to attract high-level talents to carry out technological innovation work in enterprises. In the final analysis, the brand of an enterprise comes from its product quality. However, the quality of products cannot be obtained by copying other people's ideas and techniques and cannot be obtained 


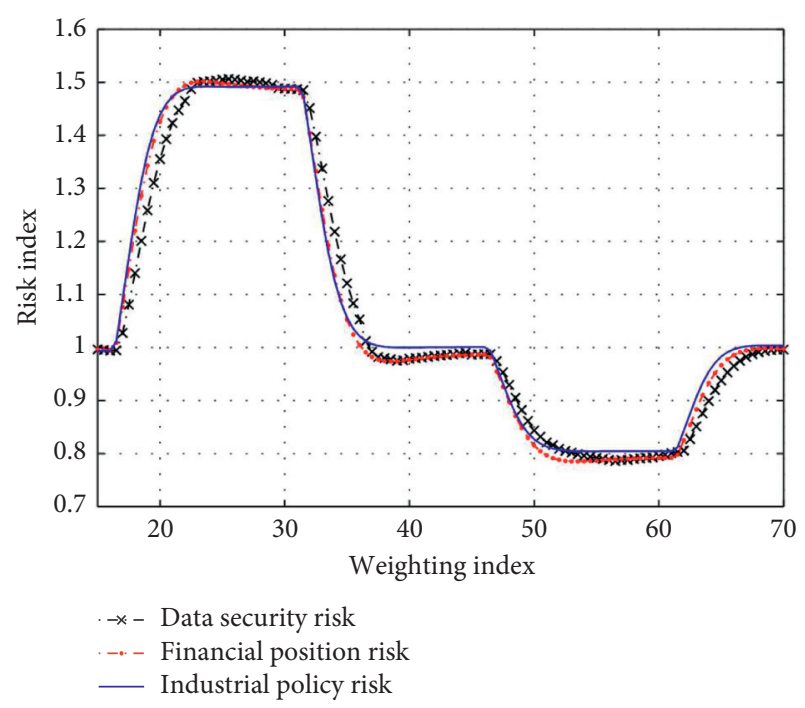

FIGURE 13: Data relationship between the weight value and the evaluation value.

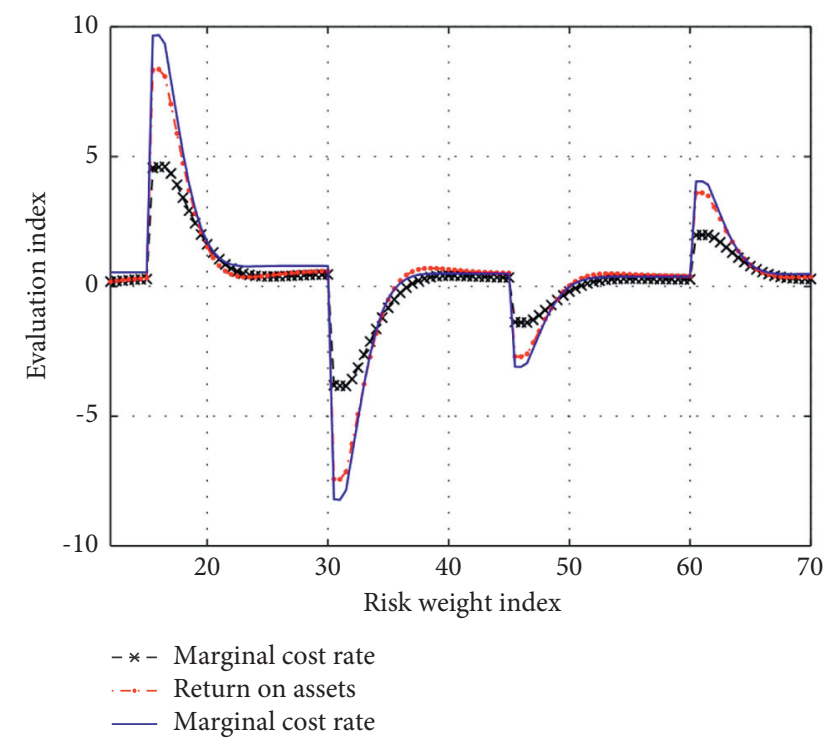

FIGURE 14: The relationship between the risk weight of financial status and the evaluation data.

through the same packaging. If modern enterprises want to build their own brands, they must start with products, and only good products can truly establish their own brands.

\section{Conclusion}

Enterprise technological innovation is the basic motive force of developing enterprise culture, and building enterprise culture will become the source of innovation motive force. Enterprise culture and technological innovation are a complex causal relationship, and they influence each other. Technological innovation is conducive to the establishment of enterprise culture and plays an important role in improving and developing enterprise value and business philosophy. If an enterprise sets up the value concept of pursuing development and change, it will inevitably strengthen the input of enterprise resources and increase the introduction of advanced technology. Enterprise culture innovation, such as the construction of learning enterprise culture, cannot be separated from enterprise practice, and enterprise technology innovation practice is the opportunity of learning enterprise culture construction. Every enterprise has its own idea, and entrepreneurs work hard toward this idea. Entrepreneurship guides the overall development strategy of enterprises from a strategic and macro perspective and at the same time directly affects the level of technology research, development, and management. Therefore, we must pay attention to the construction of learning enterprise culture in the company's technological innovation practice and find the starting point for work. So as to promote the orderly and efficient construction of learning enterprise culture in the company's technological innovation practice.

5.1. Future Work. This work can be further extended on a macro level. The enterprise culture as discussed above plays a significant role in company's technological innovation practice. It determines the health and growth or success of a company dependent on its innovation capabilities. This proposed work can be implemented in companies so that they can draw maximum benefit out of it.

\section{Data Availability}

The data used to support the findings of this study are included within the article.

\section{Conflicts of Interest}

The authors declare that they have no conflicts of interest.

\section{Acknowledgments}

This work was supported by Research on Upgrading Strategy of Guangdong New Media Marketing System Based on Big Data, funded by Research Platform and Project Young Innovative Talents of Guangdong University in 2019 by Department of Education of Guangdong Province (Project No. 2019GWQNCX103).

\section{References}

[1] F. Ramella, “The 'Enterprise of Innovation' in hard times: corporate culture and performance in Italian high-tech companies," European Planning Studies, vol. 25, pp. 1-22, 2017.

[2] J. I. A. N. Yu, "Technological innovation leads the way in enterprise cultural development-celebrating the achievements of henrianne technology Co. Ltd," China Today, vol. 35, no. 10, pp. 63-65, 2015.

[3] E. Henry, J. Newth, and C. Spiller, "Emancipatory Indigenous social innovation: shifting power through culture and technology," Journal of Management and Organization, vol. 23, no. 6, pp. 786-802, 2017. 
[4] Z. Y. Zhao, Y.-X. Li, Y.-F. Yu, and F. Yi, "Deep learning algorithm based on extreme learning," Computer Engineering and Design, vol. 16, no. 4, pp. 1022-1026, 2015.

[5] H. L. Hu, W. Wei, and M. N. Hu, "The principle and application of deep learning algorithms," Information \& Technology, vol. 24, no. 2, pp. 175-177, 2015.

[6] C. Guo, L. F. Wu, J. P. Du, K. Bao, and Q. Li, "Deep learning algorithm of correlation between atmospheric electric field data and lightning," Signal Processing, vol. 33, no. 4, pp. 607-612, 2017.

[7] X. D. Yu, W. J. Chen, D. Wang, Y. Cao, and H. Chen, "Deep learning algorithm for contactless identity recognition," Journal of Xi'an Jiaotong University, vol. 53, no. 4, pp. 122-127, 2019.

[8] N. Yao, "Research on the application of deep learning technology under the background of big data," Information and Computer, vol. 425, no. 7, pp. 151-152, 2019.

[9] S. W. Zhang, "Research on intelligent classification based on deep learning algorithms," Journal of Beijing Institute of Graphic Communication, vol. 26, no. 3, pp. 72-74, 2018.

[10] P. Hugo, N. M. T. De, and F. Chanda, "Knowledge and cooperation determinants of innovation networks: a mixedmethods approach to the case of Portugal," Journal of Technology Management and Innovation, vol. 10, no. 1, pp. 83-102, 2015.

[11] D. W. L. Hsu, Y.-C. Shen, B. J. C. Yuan, and C. J. Chou, "Toward successful commercialization of university technology: performance drivers of university technology transfer in Taiwan," Technological Forecasting and Social Change, vol. 92, no. 92, pp. 25-39, 2015.

[12] H. S. Dunn, "Creative resilience and globalization from within: evolving constructs for analysing culture, innovation, and enterprise in the global south," Annals of the International Communication Association, vol. 44, pp. 1-15, 2018.

[13] T. Krasnicka, W. Glod, and M. Wronka-Pospiech, "Management innovation, pro-innovation organisational culture and enterprise performance: testing the mediation effect," Review of Managerial ence, vol. 12, no. 3, pp. 737-769, 2018.

[14] S. Laforet, "Effects of organisational culture on organisational innovation performance in family firms," Journal of Small Business and Enterprise Development, vol. 23, no. 2, pp. 379-407, 2016.

[15] R. Rahimi, "Customer relationship management (people, process and technology) and organisational culture in hotels," International Journal of Contemporary Hospitality Management, vol. 29, no. 5, pp. 1380-1402, 2017.

[16] K. Bronson, "Responsible to whom? Seed innovations and the corporatization of agriculture," Journal of Responsible Innovation, vol. 2, no. 1, pp. 62-77, 2015.

[17] H. Song, "Comprehensive evaluation of E-commerce performance in small and medium-sized tourism enterprises: a resource-based analysis," International Journal of Multimedia and Ubiquitous Engineering, vol. 10, no. 8, pp. 139-148, 2015.

[18] S. Hashemkhani Zolfani, M. Sedaghat, R. Maknoon, and E. K. Zavadskas, "Sustainable tourism: a comprehensive literature review on frameworks and applications," Economic Research-Ekonomska Istraživanja, vol. 28, no. 1, pp. 1-30, 2015.

[19] J. Hoogerwerf, "The wright company: from invention to industry by edward J. Roach," Technology and Culture, vol. 56, no. 3, pp. 103-105, 2015. 